\title{
Numerical Simulation to Investigate the Occurrence of Vortices at Double Vertical Pumps Intakes.
}

\author{
Ali Fakhri Kadhim ${ }^{1,}$, Hayder A. Al Thamiry ${ }^{2}$, \\ ${ }^{1}$ College of Engineering, University of Baghdad, Baghdad, Iraq, E-mail: a.kadhim1310@coeng.uobaghdad.edu.iq \\ ${ }^{2}$ College of Engineering, University of Baghdad, Baghdad, Iraq, E-mail: hy_hyder@coeng.uobaghdad.edu.iq \\ * Ali Fakhri Kadhim, E-mail: a.kadhim1310@coeng.uobaghdad.edu.iq \\ Published online: 31 March 2021
}

Abstract - The pumping station is widely used in our modern life. The occurrence of the vortex at pump sump, which is causing air entering pipe intake, is a common problem in the design of pumps. This phenomenon, including surface and sub-surface vortex, may lead to damage to the pumping structure, high power consumption, and loss in pump performance. In some requirements, the multiple suction pipes are using to get the required flow. Due to this arrangement, the performance of the suction pipes will influence. This paper is aimed to investigate the occurrence of vortices around the flow pattern of two pumps by using Computational Fluid Dynamic (CFD) code Fluent. This CFD model is based on solving Navier-Stock equations by finite volume method. The model of double suction pipes was investigated under five different submergence depth (S) and five different suction velocities (v). The SST k- $\omega$ turbulence model was selected for the turbulence. The results showed that the air entering vortex does not appear when the submergence depth (S) is equal or greater than 1.5 times from the diameter of the bellmouth for intake pipe (D). The surface vortex appeared obviously when the submergence depth (S) equals to $1.25 \mathrm{D}$ and the Froude number at the bell is equal to or greater than 1.028 , and appeared clearly when the $(\mathrm{S} / \mathrm{D}=1)$ and Froude number is equal to or more than 0.77 . The nearer attached wall vortex does not appear when the space from the center of the suction pipe to the sidewall (C) equals 2 times of bell diameter.

Keywords-CFD, Occurrence of a vortex, double intakes, pump sump.

\section{Introduction}

Pumps are widely used in providing drinking water, power generation systems, drawing water from rivers and reservoirs, water cooling systems for power stations, etc. The need for using pumps continuously without problems is very highly important. The common problem facing the operation of pumps is the air entering the intakes causing cavitation phenomena. It may lead to a reduction in flow rate, noise due to vibration, high electrical consumption and may cause damage to the pumping system.

The reviewing of the literature that had been studied by $\mathrm{Li}$, et al., 2006 in [7] use a 3-D (CFD) model for the single suction pipe to get the complexity in the intakes of the pumps, they tried to use it in the design or fixing of the related problems may effect on the performance of the pumps. The model predicted good results of future use of the three-dimensional model in simulating flow in waterpump intakes. Shukla, et al., 2008 [8], used a commercial
CFD package to study air entrainment at low water level in a pump sump. They used swirl meter installed in the entrance of the suction pipe to analyze the swirl in the laboratory test and concluded that the results of the (CFD) model were satisfactory accurate in the size, strength, and location of the vortex that appeared in the experimental model. Laine, et al., 2012 in [1] carried out a numerical CFD model for a single suction pipe using the commercial code of STAR CCM+ to study the influence of air entering. The experimentations model conducted in the Hydraulic Laboratory of the (University de Génie Civil) in Damas. They used the intake pipe had interior diameter as (180 $\mathrm{mm})$. They used four ratios for the submergence of the sump (S) to the bell mouth diameter S/D $(1.5,2,2.5,3)$, four ratios for the distance between pipes and back walls $(\mathrm{a} / \mathrm{D}=0.5,0.75,1,1.25)$, four ratios for the clearance of the suction pipe to the floor $(\mathrm{z} / \mathrm{D}=0.3,0.5,0.75,1)$ and tested 192 cases for the experimental model. They carried out all tests with a constant discharge of $(18 \mathrm{l} / \mathrm{s})$. They concluded that Part of the results of (CFD) model showed 
a good agreement with experimental visualization. They showed that the results of the (CFD) proved that the basic characteristics of the flow in the pump sump and intake are unsteady, unstable, and discontinues whatever the turbulence model was used. Athab, et al., 2017 in [2] carried out an experimental model of three pumps to study the setting of the multiple vertical entrance suction pipes in the stormwater pumping station. they analyzed six factors may affect on vortices formation in pump sump, the velocity of inlet suction pipe (v), the submergence depth (s), the space between the suction pipes centerline (b), the distance of the clearance between the floor and the suction pipes (z), the effect of the distance to the back wall (a) and the effect of adding baffles between the suction pipes. They conducted 1350 runs to conclude the best hydraulic conditions of the flow in the sump. They measured the diameter of vortices that were formed and the height of it. The results showed that the formation of free surface and sub-surface vortices were mainly affected by flow velocity, followed by pipes spacing (b), back wall distance (a), and submergence (s), and to less influenced by the clearance to the floor $(\mathrm{z})$. And they introduced formula to determine the critical submergence as a relation with geometrical and hydraulic parameters. Khanarmuei, M., et al in 2018, [5] carried out an experimental model to study the effect for the direction of dual intake on vortices formation and critical submergence. They examined the influence of using different intake angles (angles of $0^{\circ}$, $45^{\circ}$, and $90^{\circ}$ ) on the formation of vortices and critical submergence. The Results of the tests showed that the use of varying angles of intake from vertical to horizontal decreased strength of vortices by $35 \%$ for single and $31 \%$ for dual intakes. Guo, et al., 2019 in [4] studied the influence of suction pipe intake condition on the appearance of the vortex in pump sump. They worked on an experimental model of pump sump that had been designed and executed with a single pipe to validate the happening of the vortex. In this study, the researchers recorded the value of flow rates which gave the critical submergence. They found that the relationship between discharge and water level was approximately linear. The concluded that the velocity of the vortex core and water swirl is high, and the pressure in the region of the core is lower than in other regions.

This study aimed to investigate the occurrence of vortices and studying the parameters affecting the vortex formation at pump sump and intakes with limited dimensions and different submergence depths and suction velocities.

\section{Mathematical Modeling}

The process to construct a CFD model generally include a geometry, meshing generation, solver with the appropriate material and boundary conditions, and finally, post-processing which includes the results of visualization for suitable graphical representations, such as vector plots, streamlines or contours, etc.

\subsection{The geometry of the model and meshing.}

The geometries of 3D models for the flow domain of pump sump and pump intakes pipes were generated by using SOLIDWORKS 2018 software, then imported in ANSYS Fluent 19. The SOLIDWORKS software used for drawings of the geometric details and helps to sketch out ideas and experiments with exact dimensions. Figs. 1 and 2 show the geometry details of pump sump and the intake pipes. Geometries were built to investigate the occurrence of vortices with bell diameter (D) as $76.2 \mathrm{~mm}$, suction pipe diameter (d) as $50.8 \mathrm{~mm}$, and the tank length $(970 \mathrm{~mm})$, and width $(610 \mathrm{~mm})$. The distance from the intake suction pipe center to the back wall (a) and the clearance of the suction pipe to the floor (z) was set according to (ASNI/HI 9.8.) [3] at $(0.75 \mathrm{D})$ and $(0.5 \mathrm{D})$ respectively. The distance between intake suction pipes (b) was set constant as (4D) and the sidewall distance (c) was (2D).



Fig. 1: the geometry of the mathematical model.

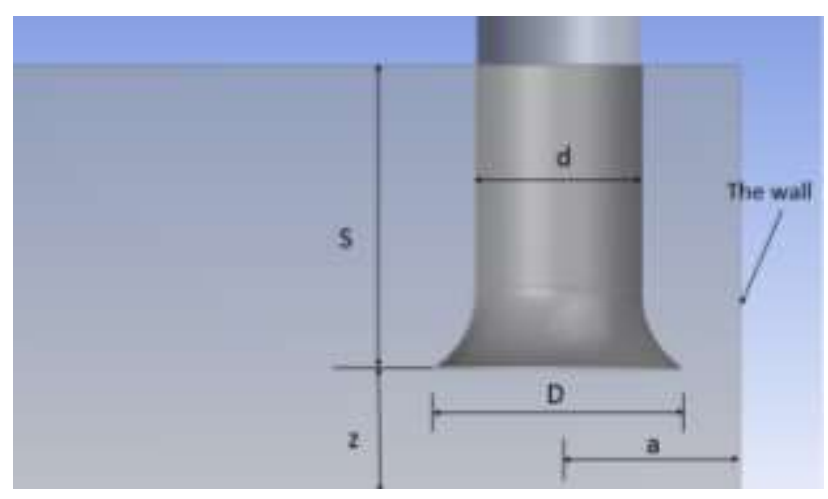

Fig. 2: the geometry details

After completing the geometry, it was exported to the ANSYS Fluent 19 code, which was used to generate meshing and solving the governing equation. The tetrahedral mesh was used to get high-quality meshing in this study. Fig. 2 show the generated mesh for geometry. 


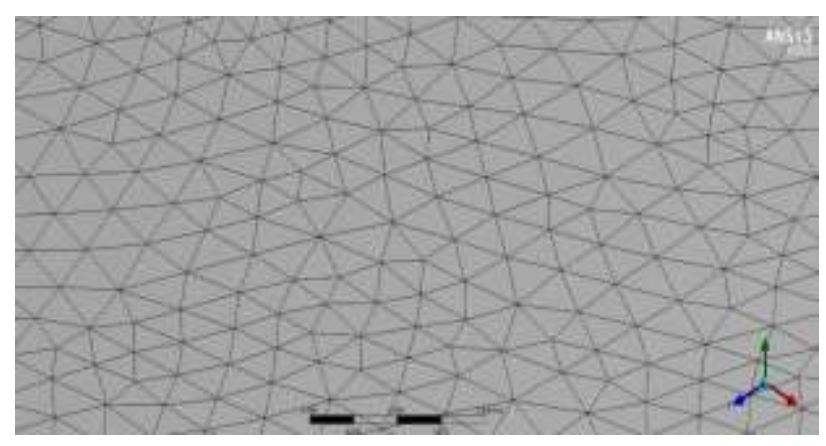

Fig. 3: the meshing of the mathematical model

\subsection{The numerical simulation applied to pump sump and intakes.}

The commercial CFD code Fluent was used in the simulation of the flows of fluids in pump sump and intakes. This simulation considers one of the best ways to avoid using the large scale model that may construct in the laboratory tests of the hydraulic model. The ANSYS Fluent 19.0 software was used in this study as a solver. The flow through the pump sump and intakes is incompressible and turbulent. ANSYS Fluent solves numerically the Navier-Stokes equations and continuity by finite volume method, which are based on principles of physics mass conservation and Newton's Second Law within a moving fluid. The model run by applied unsteady state analysis and the turbulence model (SST k- $\omega$ ) was used for turbulence.

The Boundary Conditions which was used in this analysis for the pump sump and intakes are defined by the conditions of its inlet and outlet. The boundary condition of CFD analysis was specified velocity inlet of the water in the inlet face of the tank for each case, suction velocity in the outlet of each suction pipe, and the top of the tank was free surface.

Fig 4. Show the description and summarize the runs of the model. The model investigated under five different submergence depth $(\mathrm{S}=1 \mathrm{D}, 1.25 \mathrm{D}, 1.5 \mathrm{D}, 1.75 \mathrm{D}, 2 \mathrm{D})$, and every submergence depth investigate under five different suction velocities $(\mathrm{v}=0.75,1,1.5,2,3 \mathrm{~m} / \mathrm{s})$. Twenty-five models carried out to simulate all the required cases of study.

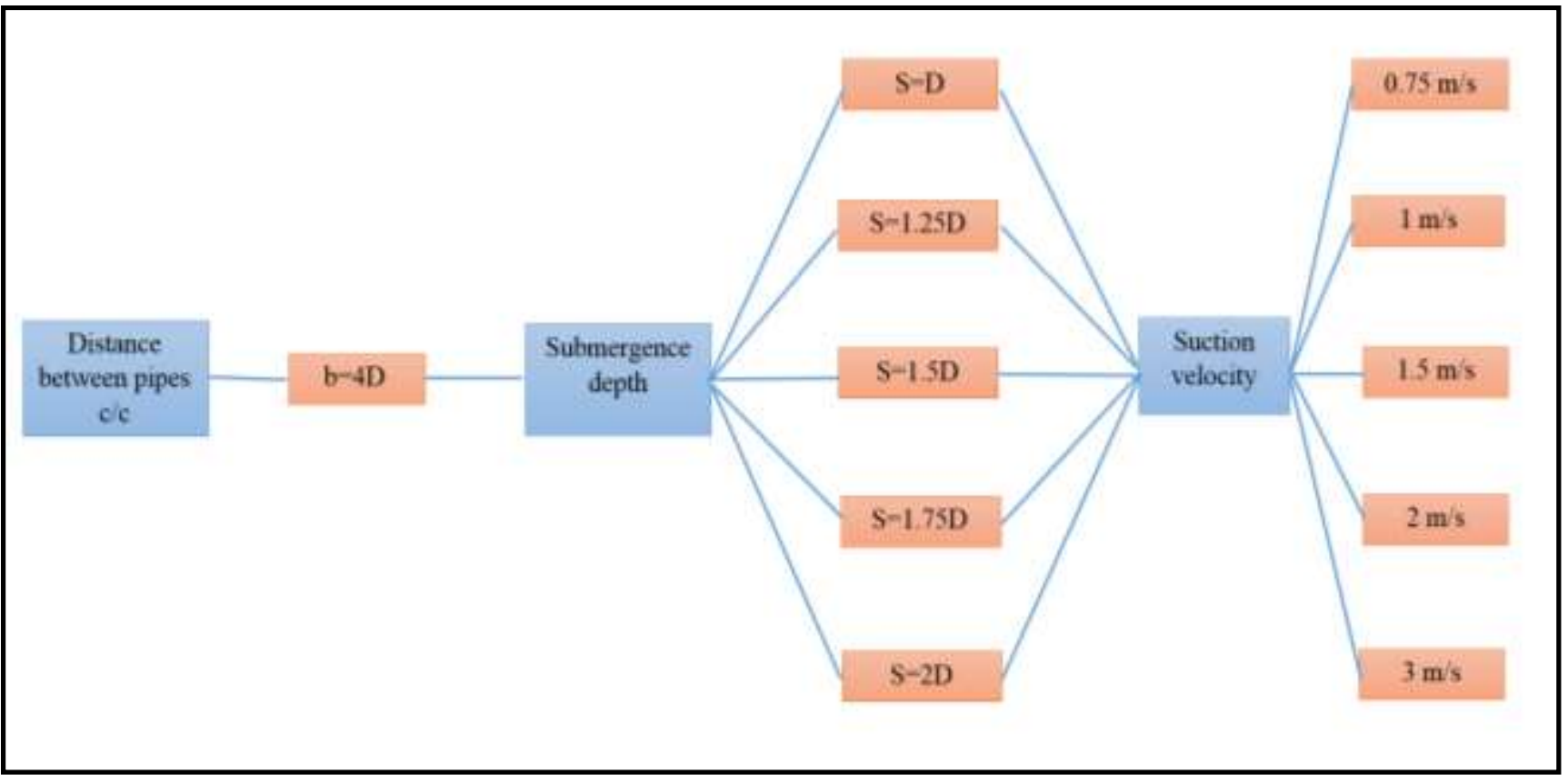

Fig 4: Plan of runs for two pumps.

\section{Simulation Results and Analysis}

The calculations were done to study the effect of different submergence depths and suction velocities on the occurrence of both surface and subsurface vortices. The results data of the numerical models collected to make comparisons between the cases of runs for discussion. ANSYS Fluent 19.0 code used to post-processing the results. The results of the numerical simulation may be analyzed with many variables. In this paper, it had been compared based on velocity profiles and the pattern of streamlines of flow.
Fig. 5 (a, and b) showed that weak vortex at the surface of the water without a gap. This type can be classified as vortex (Type 1) according to the classification of ANSH/HI 9.8 [3] standards, which look like surface ring swirl, this type of vortex is not affecting on the operation of pumps and not dangerous. The vortex (Type 2 and Type 3) [3] also can be no danger on the performance of the pumps because it rarely sucks air to the intake pipe. The results showed that these types of vortices appeared when the ratio of submergence depth to the bell diameter was $(\mathrm{S} / \mathrm{D} \geq 1.5)$.

Fig. 5 (c, d, e, and f) showed that vortex (Type 4) [3] appeared in the model. This type of vortex and (Type 5 and 
6) [3] is likely to avoid it. It causes pulling air to the intake pipe, as a result, it leads to damage in the pumping system and reduction in the required flow rate. The result showed that this type appeared obviously when the submergence was equal to 1.25 from the bell diameter and the suction velocity was equal or greater than $2 \mathrm{~m} / \mathrm{s}$ or the Froude Number at the bell equals to or more than 1.028. Moreover, these types appeared clearly when the submergence depth



(a)



(c) was equal to the bell diameter and the suction velocity equals to or greater than $1.5 \mathrm{~m} / \mathrm{s}$ or the Froude number at the bell equals to or more than 0.77 .

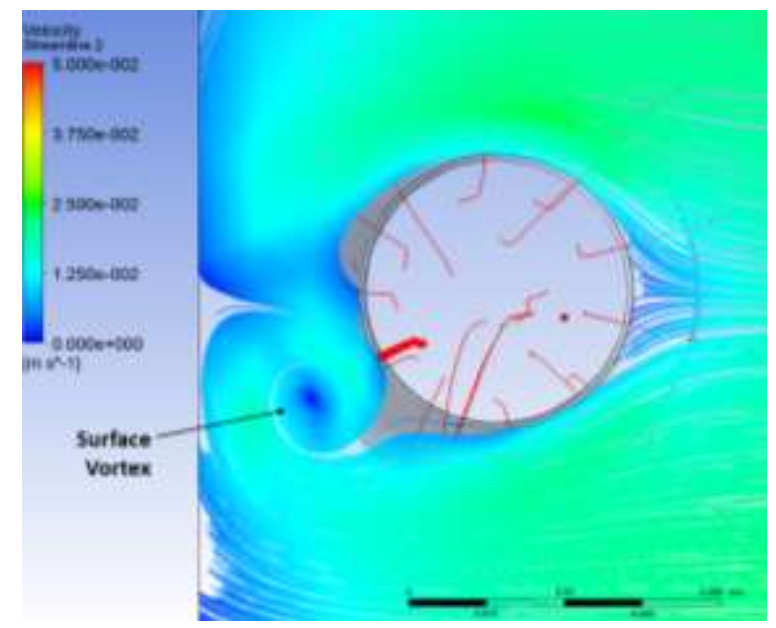

(b)



(d) 




(e)



(f)

Fig. 5: (a, b, c, d, e, and f) Surface vortex appeared in the numerical model.

A cut plan was placed at the bottom and sidewalls of the tank to investigate the subsurface vortices. The results showed a weak vortex may appear in the bottom of tanks and no subsurface vortices appeared in the side walls. [2] conclude that the subsurface vortex does not occur when the spaces between pipes (b) are greater than 3D and the submergence depth to the bell diameter ( $/ \mathrm{D} \geq 1.25)$.

\section{Conclusion}

This study dealt with the occurrence of vortices at dual pump intakes using numerical simulation. The study was limited under some constant geometry dimensions and varying submergence depth and velocities. The results showed that:

1. The opportunity of occurrence of the vortex will increase with decrease submergence depth and increase the velocity.

2. The air entering vortex did not appear when the ratio of submergence depth to the bell mouth diameter was $(\mathrm{S} / \mathrm{D} \geq 1.5)$.

3. The pulling air vortex appeared clearly when the submergence became 1.25 from the bell mouth diameter and the suction velocity was equal to or greater than $2 \mathrm{~m} / \mathrm{s}$.

4. When the submergence depth is equal to the bell diameter $(S / D=1 D)$, the air entering vortex appeared obviously with a suction velocity equal to or greater than $1.5 \mathrm{~m} / \mathrm{s}$.

5. The nearer wall vortex did not appear when the distance between the center of the intake pipe to the sidewall equal to two times of the bell diameter (c/D $=2 \mathrm{D}$ ), and the results showed that a weak strength attaches floor vortex has appeared which can not consider danger on the performance of pumps.

\section{References}

[1] A. C. B. Laine, S. Simonet, G. Bois, and A. Issa, 2012. "Two-phase numerical study of the flow field formed in water pump sump: influence of air entrainment," 26th IAHR Symposium on Hydraulic Machinery and Systems, IOP Conf., Earth and Environmental Science, available online DOI:10.1088/1755-1315/15/2/022007.

[2] A. H. Athab, H. M. M. Al-Khateeb, and H. A. K. AlThamiry, "Investigating the Setting of the Entrance of Multiple Vertical Suction Pipes in Storm Water Pump Station," International Advanced Research Journal in Science, Engineering and Technology, vol. 4, no. 8, pp 69-78, Aug. 2017.

[3] Hydraulic Institute Standards, American National Standard for Pump Intake Design, ANSI/HI 9.8., 1998.

[4] M. Guo, Z. Chen, and Y., Choi, 2019, "Effect of suction pipe inlet condition on the occurrence of the vortex in pump sump," 29th IAHR Symposium on Hydraulic Machinery and Systems, Earth and Environmental Science, available online DOI:10.1088/1755-1315/240/6/062023.

[5] M. Khanarmuei, H. Rahimzadeh, and H. Sarkardeh, 2018. "Effect of dual intake direction on critical submergence and vortex strength," Journal of Hydraulic Research, [Online] Available at: (http://www.tandfonline.com/loi/tjhr20).

[6] N. Szeliga, L. H. Elgott, D. Bezecny, S. Richter, M. Hoffmann, and M. Schluter, 2019. "Large-Scale Experiments on the Formation of Surface Vortices with and without Vortex Suppression," WILEYVCH Verlag GmbH \& Co. KGaA, Weinheim, vol. 91, no. 12 , pp., 1-11. 
[7] S. Li, J. M. Silva, Y. Lai, L. J. Weber, and V. C. Patel, 2006. "Three-dimensional simulation of flows in practical water-pump intakes," Journal of Hydroinformatics, available online at DOI: 10.2166/hydro.2006.015b
[8] S. N. Shukla, and J. T. Kshirsagar, 2008. "Numerical prediction of air entrainment in pump intakes," Available online, https://www.911metallurgist.com/blog/wpcontent/uploads/2016/01/Numerical-Prediction-ofAir-Entrainment-in-Pump-Intakes.pdf

\title{
المحاكاة العددية للتحقق من حدوث الاوامات في مآخذ المحطات العمودية المزدوجة.
}

\author{
علي فخري كاظم1 ، "، حير عبد الأمير الثامري2 \\ كلبة الهندسة، جامعة بغداد، بغداد، العراق، a.kadhim1310@coeng.uobaghdad.edu.iq \\ hy_hyder@coeng.uobaghdad.edu.iq، كلبة الهندسة، جامعة بغد/د، بغد/د، العر/ق \\ a.kadhim1310@coeng.uobaghdad.edu.iq علي فخري كاظم، البريب الالكتروني،
}

شر في: 31 اذار 2021 - مي

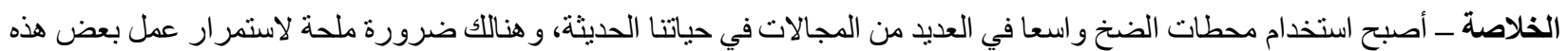



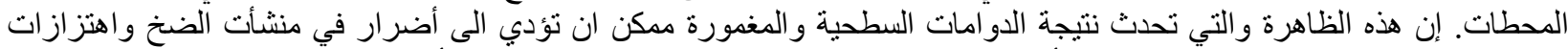



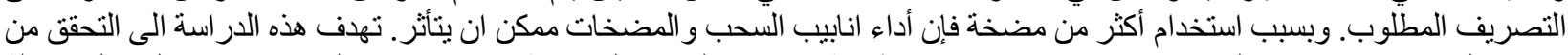



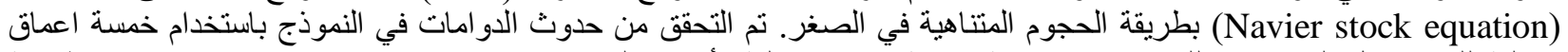

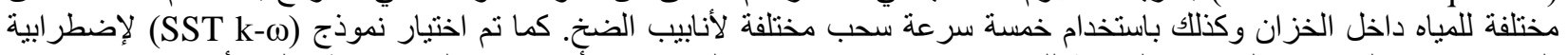



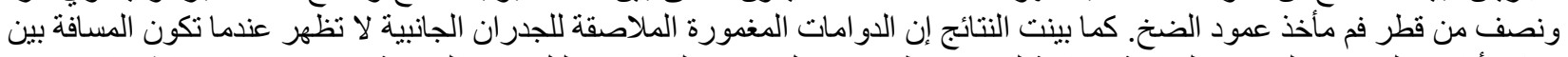





